\title{
Análise do supercapacitor em operando através da microscopia Raman
}

\section{Vinícius Augusto Lima*, Hudson Giovani Zanin}

\section{Resumo}

O capacitor eletroquímico armazena energia em um campo eletrostático, sendo uma fonte ideal para o armazenamento e liberação rápida de energia. Um mecanismo experimental foi proposto para investigar o processo de intercalação de íons no supercapacitor. Durante o processo de carga e descarga do supercapacitor, foi realizado uma análise através da microscopia Raman e observou-se os picos D, G e 2D referentes ao eletrodo a base de carbono, além de um pico em $1000 \mathrm{~cm}-1$ que representa a solução $\mathrm{SO}_{4}$ e para potenciais positivos apresenta maior intensidade.

\section{Palavras-chave:}

Microscopia Raman, Supercapacitor, Intercalação.

\section{Introdução}

O supercapacitor é um dispositivo que tem a finalidade de armazenar energia elétrica. É composto por dois eletrodos e uma membrana porosa e o conjunto é mergulhado em um eletrólito. Ao aplicar uma diferença de potencial, os íons do eletrólito são atraídos para os eletrodos, iniciando assim o processo de carga. Ao cessar a potencial, o processo se encerra, formando um ciclo reversível.

O presente trabalho tem como objetivo estudar uma das interações entre os íons do eletrólito e os eletrodos, a intercalação. Durante a intercalação, os íons acessam os poros dos eletrodos, mudando o seu volume, que por sua vez pode causar dano na interface entre eletrólito e eletrodo, diminuindo assim sua vida útil.

\section{Resultados e Discussão}

A célula do supercapacitor foi construída utilizando dois eletrodos de grafite e um separador de papel entre eles para evitar o contato. Para o eletrolítico foi escolhido 1 mol de $\mathrm{Li}_{2} \mathrm{SO}_{4}$ em meio aquoso.

Os eletrodos foram utilizados como material de estudo dentro de uma célula Raman in situ, conforme a figura 1. A célula é isolada da atmosfera, permitindo processos eletroquímicos serem investigados em operação. A abertura na célula permite que um laser Raman seja focalizado na superfície do eletrodo durante o ciclo eletroquímico, de modo que os espectros Raman sejam obtidos em função do potencial aplicado.

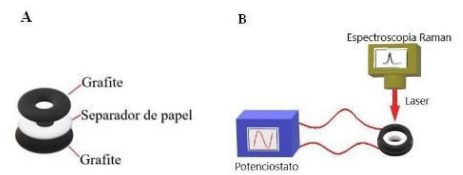

Figura 1. (A) Esquema da célula do supercapacitor; (B) Representação da célula no Raman em operação.

Foram realizados ciclos de carga e descarga no capacitor, variando o potencial aplicado no eletrodo a partir do potencial negativo $-1 \mathrm{~V}$ e implementando $0,2 \mathrm{~V}$ até chegar no potencial positivo de $1 \mathrm{~V}$.

Os principais picos apresentados nos dois gráficos da figura 2 referentes ao grafite são as bandas
$D, G$ e $2 D$ observadas em $1336 \mathrm{~cm}^{-1}, 1580 \mathrm{~cm}^{-1} \mathrm{e}$ $2670 \mathrm{~cm}^{-1}$ respectivamente. O pico $\mathrm{G}$ é devido ao movimento relativo dos átomos com ligação $\mathrm{sp}^{2}$ nos anéis e nas cadeias, que são os movimentos interplanares.

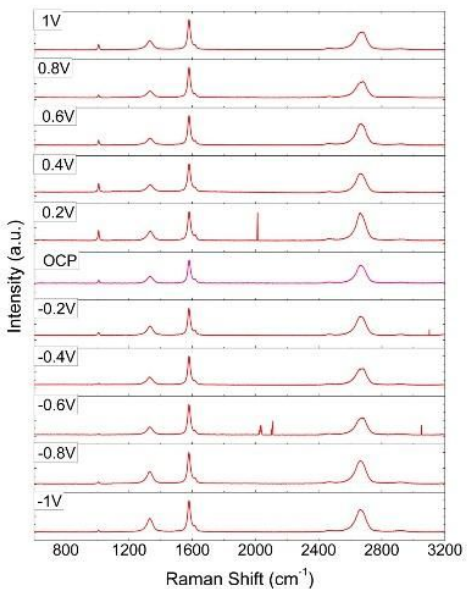

Figura 2. Espectroscopia Raman in Situ

O pico $D$ é devido aos modos respiratórios de átomos $\mathrm{sp}^{2}$ em anéis, ou seja, desordem na rede cristalina. Observou-se um pico em $1000 \mathrm{~cm}^{-1}$ que varia sua intensidade de acordo com o potencial aplicado. Para potenciais positivos, apresenta maior intensidade. $O$ pico de $1000 \mathrm{~cm}^{-1}$ representa a solução de $\mathrm{SO}_{4}$, que quando no formato de íon $\mathrm{SO}^{2}$ - é atraído pela força coulombiana para o eletrodo de grafite que apresenta potencial positivo.

\section{Conclusões}

Os resultados indicam que o potencial aplicado entre os eletrodos têm muita influência na ligação eletroquímica entre os íons do eletrólito e os eletrodos. A partir de um determinado potencial positivo, o pico referente a solução $\mathrm{SO}_{4}$ aumenta a sua intensidade. Novos experimentos com diferentes eletrólitos são necessário para melhor entendimento sobre os mecanismos que controlam o supercapacitor.

\section{Agradecimentos}

O primeiro autor agradece a CNPq pela bolsa PIBIC a qual permitiu a realização dessa pesquisa. 